\title{
Folate transport in enterocytes and brush-border-membrane vesicles isolated from the small intestine of the neonatal goat
}

\author{
BY PETER BLAKEBOROUGH \\ Department of Food Quality and Human Nutrition, AFRC Institute of Food Research, \\ Reading Laboratory, Shinfield, Reading RG2 9AT \\ AND DALLYN N. SALTER \\ Department of Pig Nutrition and Production, AFRC Institute of Grassland and Animal \\ Production, Shinfield, Reading $R G 29 A Q$
}

(Received 1 December 1987 - Accepted 15 January 1988)

1. The uptake of 5-methyltetrahydrofolate (MTHF) and folic acid (pteroylmonoglutamate) by enterocytes and brush-border-membrane vesicles prepared from the small intestine of the 6-d-old male goat was determined using a rapid-filtration assay.

2. Both MTHF and folic acid were taken up by membrane vesicles at $25^{\circ}$ and enterocytes at $37^{\circ}$ by a $\mathrm{pH}$ dependent mechanism with maximum uptake when the $\mathrm{pH}$ of the incubation medium was $5 \cdot 0$.

3. Experiments in which the osmotic pressure of the medium was raised in successive increments with the nonabsorbable sugar cellobiose indicated that transport rather than membrane binding was the main component of uptake.

4. Experiments at $\mathrm{pH} 5.0$ showed that uptake of MTHF and folic acid was saturable and that the characteristics of folate transport were similar in both tissue preparations : (a) transport rates of both MTHF and folic acid were constant during the first 1-2 min for a given folate concentration, then declined to reach a steady-state in 10$30 \mathrm{~min}$; (b) initial velocities of transport of MTHF and folic acid increased in proportion to their concentrations up to 7-10 $\mu \mathrm{M}$, but the rate of increase slowed thereafter until saturation was reached at $20-25 \mu \mathrm{M}\left(K_{m}\right.$ for brushborder-membrane vesicles 40.8 and $62.9 \mu \mathrm{M}, K_{m}$ for enterocytes 50.9 and $55.2 \mu \mathrm{M}$ for MTHF and folic acid respectively). Values of $V_{\max }$ for membrane vesicles (pmol $/ \mathrm{mg}$ protein per min) were $46.5 \mathrm{MTHF}$ or 40.3 folic acid; enterocytes $V_{\max }$ (pmol/10 $10^{7}$ cells per min) 15.9 MTHF or 30.6 folic acid; (c) uptake of MTHF and folic acid by brush-border-membrane vesicles and enterocytes measured under steady-state conditions approached saturation at $50 \mu \mathrm{M}$ for each analogue $\left(K_{m}\right.$ for membrane vesicles $58 \cdot 1$ and $55 \cdot 2 \mu \mathrm{M}, K_{m}$ for enterocytes $43 \cdot 1$ and $49 \cdot 4 \mu \mathrm{M}$ for MTHF and folic acid respectively; $V_{\max }$ for membrane vesicles $49 \cdot 7$ and $77.8 \mathrm{pmol} / \mathrm{mg}$ protein, for enterocytes 52.8 and $54.7 \mathrm{pmol} / 10^{7}$ cells for MTHF and folic acid respectively).

5. It was concluded that transport of MTHF and folic acid was by a similar $\mathrm{pH}$-dependent mechanism both in brush-border-membrane vesicles and in intact enterocytes. At $\mathrm{pH} 5.0$, transport involved a saturable carriermediated process located in the brush-border membrane.

Brush-border-membrane vesicles isolated from the whole small intestine have recently been used to study folate absorption in the rat (Selhub \& Rosenberg, 1981). It was claimed that the properties of brush-border-membrane vesicles should reflect events occurring at the lumen border of the cell without the complication of effects of metabolism within the enterocyte or transport at the basolateral membrane. On the other hand, Eilam et al. (1981) have used enterocytes isolated from chick intestine. Both groups found that uptake of folates took place by means of a saturable carrier-mediated mechanism, but $K_{m}$ values for folic acid (pteroylmonoglutamate) uptake differed by an order of magnitude. It is not known whether the discrepancies represent species differences or resulted from the use of two different types of preparation.

The studies presented here compare the characteristics of the folate transport process in both enterocytes and brush-border-membrane vesicles isolated from the small intestine of the 6-d-old goat. A preliminary account of this work has been presented (Blakeborough \& Salter, 1985). 


\section{Materials}

5-[ $\left[{ }^{14} \mathrm{C}\right]$ methyltetrahydrofolate (MTHF ; barium salt, $\left.58 \mathrm{mCi} / \mathrm{mmol}\right)$ and $\left[3^{\prime}, 5^{\prime}, 7,9-{ }^{3} \mathrm{H}\right]$ folic acid (potassium salt, $22 \mathrm{Ci} / \mathrm{mmol}$ ) were purchased from Amersham International plc, Amersham, Bucks and stored at $-20^{\circ}$. Dulbecco's modification of Eagles' medium (with 20 mM-Hepes but without glutamine or bicarbonate), NCTC 135 medium, fetal bovine serum and penicillin-streptomycin (5000 IU-5000 $\mu \mathrm{g} / \mathrm{ml}$ ) were all purchased from Flow Laboratories Ltd, Rickmansworth. Yeast extract and insulin (bovine pancreas) were purchased from Sigma Chemical Co., Poole, Dorset. Bactotryptone was purchased from Difco Laboratories, East Molesey, Surrey. Other chemicals were purchased from BDH Chemical Co. Ltd, Poole and were of analytical grade where possible.

\section{Buffers}

Krebs buffer 1 contained $0.154 \mathrm{M}$-sodium chloride, 0.154 M-potassium chloride, 0.154 Mpotassium dihydrogen phosphate, $0.154 \mathrm{M}$-magnesium sulphate, $0.1 \mathrm{M}$-disodiumhydrogen phosphate, $\mathrm{pH} 7 \cdot 2$. Krebs buffer 2 was prepared from buffer 1 by the addition of EDTA ( $5 \mathrm{~mm}$ ) and bovine serum albumin $(2.5 \mathrm{~g} / \mathrm{l})$. Krebs buffer 3 was prepared from buffer 1 by the addition of bovine serum albumin $(10 \mathrm{~g} / 1)$. All these buffers were ice-cold and oxygenated with oxygen-carbon dioxide $(95: 5, \mathrm{v}: \mathrm{v})$ before use.

Growth medium for enterocytes was as follows: Dulbecco's modification of Eagles' medium (with $20 \mathrm{~mm}$-Hepes but without glutamine or bicarbonate; $90 \mathrm{ml}$ ) was mixed with NCTC 135 medium $(10 \mathrm{ml})$. To this mixture was added in turn: 0.066 M-glutamine in $0.73 \mathrm{M}$-sodium bicarbonate, $6 \mathrm{ml}$; fetal bovine serum, $5 \mathrm{ml} ; \mathrm{L}$ Broth $(\mathrm{g} / 1 ; 5 \mathrm{NaCl}, 10$ bactotryptone, 5 yeast extract; Moyer, 1983), $5 \mathrm{ml}$; pituitary extract, $2 \mathrm{ml}$; insulin, $1 \mathrm{ml}$ (containing $0.5 \mathrm{mg}$ ); penicillin-streptomycin, $2 \mathrm{ml}$. These additions were used to improve the viability of the cells (Moyer, 1983) and prevent microbial growth. Aseptic techniques were used throughout.

\section{Animals}

Male kids from the Institute herd of pedigree British Saanen goats were used. They were suckled by their dams for the first $5 \mathrm{~d}$ after parturition, then fasted overnight before the experiments.

\section{Preparation of enterocytes}

At $6 \mathrm{~d}$ of age, goats were killed by injection of sodium pentobarbitone $(700 \mathrm{mg}, 3.5 \mathrm{ml}$ ) into the heart. The entire small intestine (7-10 $\mathrm{m}$ total length) was rapidly removed, washed out with ice-cold $0.15 \mathrm{M}-\mathrm{NaCl}$ and cooled on ice. For the preparation of enterocytes three $1 \mathrm{~m}$ segments were taken, one starting $1 \mathrm{~m}$ distal to the pylorus, the other starting at the midpoint between the pylorus and the ileo-caecal junction and the third $1 \mathrm{~m}$ before the ileocaecal valve, providing samples representative of the full intestine. Enterocytes were prepared essentially as described by Watford et al. (1979), except that the concentration of bovine serum albumin in the third Krebs-Hensleit medium used in the final release of cells into the gut lumen was reduced from 25 to $10 \mathrm{~g} / 1$. Cells from all segments of the small intestine were pooled at this stage. Unlike preparations from the rat and chick, the suspension obtained by this procedure consisted mainly of sheets of brush-border cells rather than single cells and it was necessary to use collagenase (EC 3.4.4.19) to separate them. Tests showed that optimum conditions for this purpose, with maximum retention of viability, were achieved by addition of collagenase $(0.2 \mathrm{mg} / \mathrm{ml})$ and shaking gently for $20 \mathrm{~min}$ at $37^{\circ}$ while continuously gassing the suspension with $\mathrm{O}_{2}-\mathrm{CO}_{2}(95: 5, \mathrm{v}: \mathrm{v})$. Higher concentrations of collagenase or the use of hyaluronidase $(E C 3.2 .1 .35)$ resulted in a loss of enterocyte viability. After incubation, the cell suspension was filtered through two layers 
of washed cheese-cloth and centrifuged at $500 \mathrm{~g}$ for $3 \mathrm{~min}$ at room temperature. The cell pellet was resuspended in $10-30 \mathrm{ml}$ growth medium (Ferland \& Hugon, 1979). The suspension was centrifuged again using the same conditions and the sedimented cells resuspended in growth medium at $0.5-3 \times 10^{7}$ cells $/ \mathrm{ml}$, held at $37^{\circ}$ and continuously gassed with $\mathrm{O}_{2}-\mathrm{CO}_{2}(95: 5, \mathrm{v}: \mathrm{v})$. The preparation took approximately $2 \mathrm{~h}$ to complete from the time of killing the animal, and uptake experiments with enterocytes commenced immediately. Preincubation times were controlled to be identical for each type of experiment.

\section{Enterocyte counts and viability}

Samples of the enterocyte preparation were taken at approximately hourly intervals during the course of experiments for total and viable cell counts. The cells were stained with a mixture of Acridine Orange and ethidium bromide and viability assessed using a modification of the method of Ford (1979) for lymphoid cells. Samples of the suspension $(100 \mu \mathrm{l})$ were mixed with an equal volume of dye solution (Acridine Orange $(0.5 \mathrm{mg} / \mathrm{ml})$ and ethidium bromide $(0.02 \mathrm{mg} / \mathrm{ml})$ in $0.05 \mathrm{~m}$-phosphate buffer, $\mathrm{pH} 7.4$, with sodium hydroxide) and counted in a haemocytometer using a fluorescence microscope. Viable cells fluoresced bright green, damaged or dead cells stained red. The proportion of viable cells in the enterocyte suspension declined gradually from 80.1 (SE 2.6) \% when first prepared to $67 \cdot 4$ (SE 4.2 ) \% after $8 \mathrm{~h}$ (mean for ten different cell preparations). Microscopic examination showed that the viable cells retained their structural integrity throughout this period.

\section{Preparation of brush-border-membrane vesicles}

Brush-border-membrane vesicles were prepared from the entire small intestine of 6-d-old goats. The intestine was excised, rinsed with ice-cold $0.15 \mathrm{M}-\mathrm{NaCl}$, then frozen at $-20^{\circ}$. Brush-border-membrane vesicles were prepared from this frozen tissue, as described by Booth \& Kenny (1974). Vesicles were frozen at $-20^{\circ}$ for storage for up to 4 months without loss of shape or enzyme activity. The purity of the vesicles was assessed by alkaline phosphatase (EC 3.1.3.1) assay, a marker enzyme for the brush border. Preparations showed purifications over the initial mucosal homogenate of 13-20-fold. Brush-bordermembrane vesicles appeared as closed, approximately circular vesicles of diameter $0 \cdot 1-0.2 \mu \mathrm{m}$ in the electron microscope under negative staining. Vesicles were maintained on ice, after thawing, until they were used in uptake experiments, which were completed within $2 \mathrm{~h}$.

\section{Experimental}

The buffers used for transport experiments in the range $\mathrm{pH} 5 \cdot 0-8.0$ were prepared from $50 \mathrm{~mm}$-Hepes, $50 \mathrm{~mm}$-Mes (2[N-Morpholino]ethanesulphonic acid), $50 \mathrm{~mm}-\mathrm{NaCl}, 1 \mathrm{~mm}$ $\mathrm{MgSO}_{4}$ adjusted to the required $\mathrm{pH}$ value with $1.0 \mathrm{M}$-hydrochloric acid. Experiments at $\mathrm{pH}$ $4.0-4.5$ were conducted in $50 \mathrm{~mm}$-sodium acetate, $50 \mathrm{~mm}-\mathrm{Mes}, 50 \mathrm{~mm}-\mathrm{NaCl}, 1 \mathrm{~mm}-$ $\mathrm{MgSO}_{4}$ adjusted with $1.0 \mathrm{M}$-acetic acid. The final volume was $0.5 \mathrm{ml}$. $\left[{ }^{14} \mathrm{C}\right] \mathrm{MTHF}$ or $\left[{ }^{3} \mathrm{H}\right]$ folic acid $(1-50 \mu \mathrm{M})$ containing $0 \cdot 03-0 \cdot 17 \mu \mathrm{Ci}{ }^{14} \mathrm{C}$ or ${ }^{3} \mathrm{H}$ were used as the substrate, and reactions were initiated by adding enterocytes $\left(0.1 \mathrm{ml}\right.$ of the suspension, $0.5-2 \times 10^{6}$ cells $)$ or brush-border-membrane vesicles ( $50 \mu \mathrm{g}$ protein). The reactions continued for $1-30 \mathrm{~min}$ at $37^{\circ}$ (enterocytes) or $25^{\circ}$ (vesicles) and were terminated by the addition of ice-cold buffer (10 mM-Mes, $0 \cdot 15 \mathrm{M}-\mathrm{NaCl}$, of the same $\mathrm{pH}$ as the incubation buffer). The lower temperature was used in experiments with vesicles since it has been shown to improve their stability. The cells or vesicles were immediately collected by rapid filtration through membranes of porosity $0.45 \mu \mathrm{m}$ (Whatman Ltd, Maidstone, Kent). Ice-cold buffer $(5 \mathrm{ml})$ was added to the sample tubes and washed through the filters to ensure quantitative transfer of the cells or vesicles. The filters were then washed with ice-cold buffer $(2 \times 5 \mathrm{ml})$ to wash away unbound radioactivity. Non-specific binding to enterocytes and vesicles was estimated with zero-time 

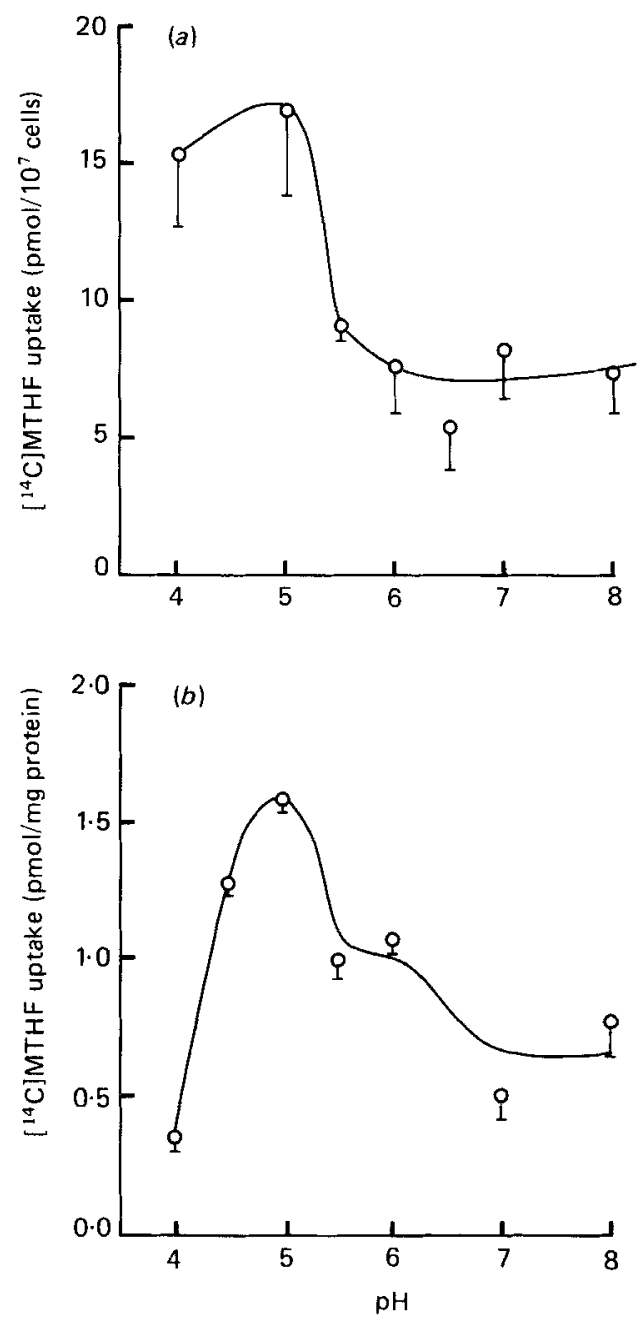

Fig. 1. The influence of $\mathrm{pH}$ on the uptake of 5-methyltetrahydrofolate (MTHF) by enteroctyes and brush-border-membrane vesicles. (a) Enterocytes and (b) brush-border-membrane vesicles were incubated with $50 \mu \mathrm{M}$ or $2 \mu \mathrm{M}\left[{ }^{14} \mathrm{C}\right] \mathrm{MTHF}$ respectively, for $15 \mathrm{~min}$ in media of $\mathrm{pH} \mathrm{4-8.} \mathrm{Results} \mathrm{are} \mathrm{the}$ means of three determinations, with their standard errors represented by vertical bars.

blanks and subtracted from experimental values. Filters were dried in air and transferred to vials. Instagel (Packard Instrument Co. Inc, Illinois, USA) $(10 \mathrm{ml})$ was added to the vials and radioactivity was estimated using liquid-scintillation counting.

\section{Assays}

Protein was assayed as described by Bensadoun \& Weinstein (1976). Alkaline phosphatase activity was assayed as described by Murer et al. (1976).

\section{Treatment of results}

Initial velocity values were plotted as uptake of folates $v$. substrate concentration. Values for the uptake of folates at steady-state were plotted as folate taken up at steady-state $v$. free unreacted folate. Values for $K_{m}$ and $V_{\max }$ were calculated from these values using a non- 


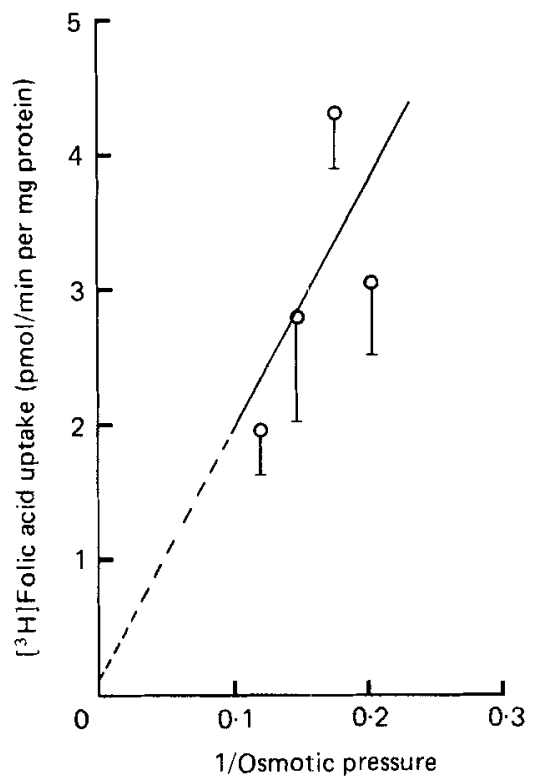

Fig. 2. The effect of increasing the osmotic pressure of the medium on the uptake of folic acid by brushborder-membrane vesicles. $\left[{ }^{3} \mathrm{H}\right]$ Folic acid $(1 \mu \mathrm{M})$ was incubated with brush-border-membrane vesicles at pH 5.0 for $1 \mathrm{~min}$ at $25^{\circ}$, in the presence of $0,10,25$ or $50 \mathrm{~g}$ cellobiose/l. Results, plotted as folic acid taken up $v$. the reciprocal of osmotic pressure, are the means of four determinations, with their standard errors represented by vertical bars. The best-fitting straight line was determined by linear regression.

linear curve-fitting package (MLP) on a Vax 11/750 computer (Digital Equipment Corporation). Results were fitted to the Michaelis-Menten equation $(y=b /(1+d x)$ where $b$ is $-V_{\max }$ and $d$ is $\left.1 / K_{m}\right)$ after converting the $y$ values to a logarithmic form $(\log y+$ constant).

\section{RESULTS}

The influence of $\mathrm{pH}$ on the uptake of MTHF by enterocytes and brush-border-membrane vesicles is shown in Fig. $1(a, b)$. Uptake was $\mathrm{pH}$ dependent and showed an optimum at $\mathrm{pH}$ 5.0 for both types of preparation. Uptake of folic acid showed a similar $\mathrm{pH}$ dependence and all subsequent experiments were done at $\mathrm{pH}$ 5.0.

The uptake of folic acid by brush-border-membrane vesicles was progressively decreased as the osmotic pressure of the incubation medium was increased with cellobiose (Fig. 2). Extrapolation of the plot of folate uptake $v$. the reciprocal of osmotic pressure indicated approximately zero uptake at infinite osmotic pressure.

The influence of the concentration of MTHF in the medium on its rate of uptake is illustrated in Fig. 3( $a$, enterocytes; $b$, membrane vesicles). Uptake was linear with respect to time for 2-5 min, the rate increasing as the concentration of MTHF increased. Subsequently, uptake slowed and by 10-30 min steady-state was established. It was not possible in these experiments to determine whether efflux of folates occurred. In both enterocytes and vesicles the uptake mechanism showed a trend toward saturation at steadystate as the concentration of MTHF increased. Results for the uptake of folic acid with respect to time were similar to those observed with MTHF (Fig. 3( $c$, enterocytes; $d$, membrane vesicles)). 

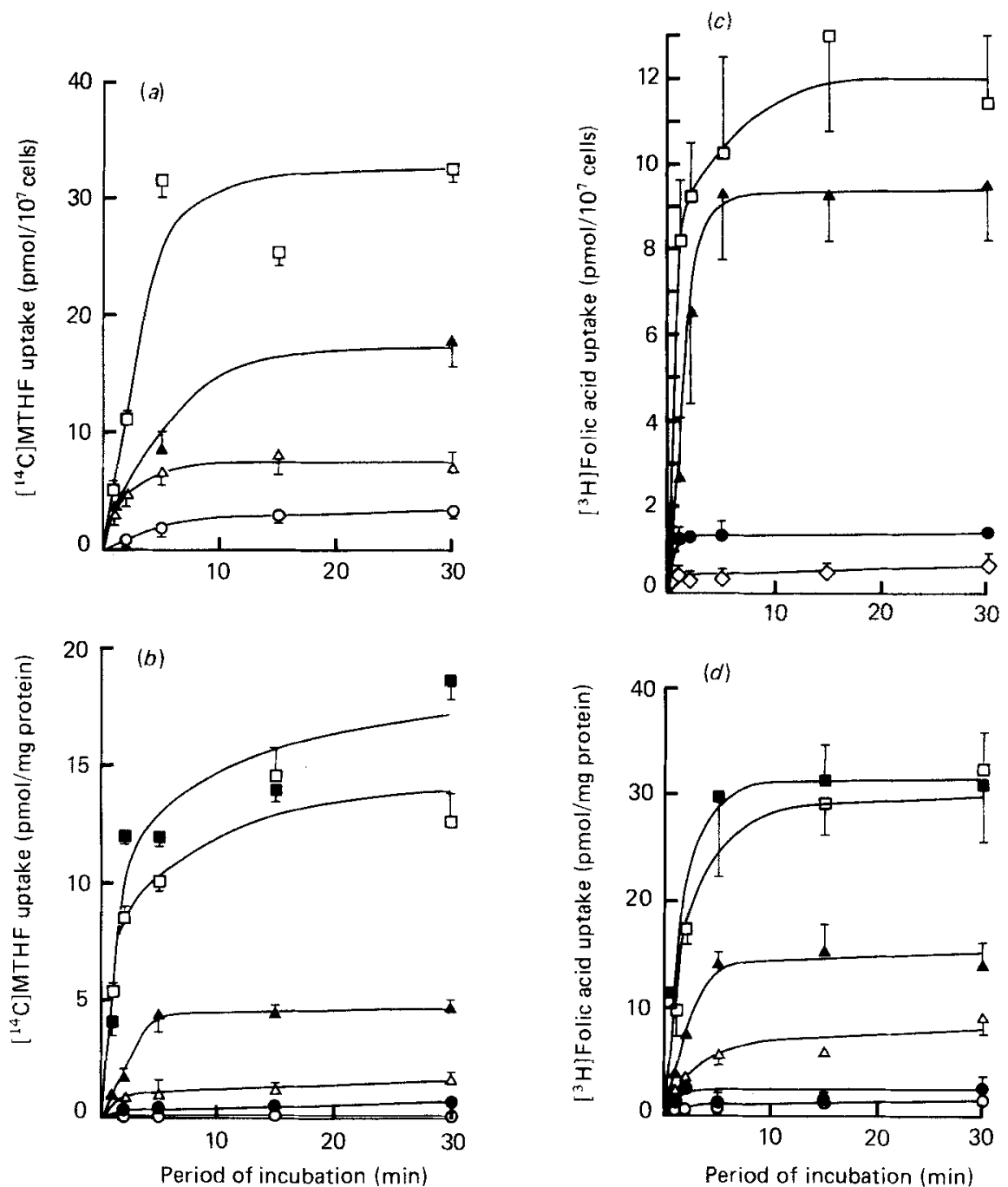

Fig. 3. The influence of incubation time and folate concentration on the uptake of folates. $(a, b) 5$ $\left[{ }^{14} \mathrm{C}\right]$ methyltetrahydrofolate $\left(\left[{ }^{14} \mathrm{C}\right] \mathrm{MTHF}\right)$ or $(c, d)\left[{ }^{3} \mathrm{H}\right]$ folic acid were incubated with enterocytes $(a, c)$ or brush-border-membrane vesicles $(b, d)$ at $\mathrm{pH} 5.0$ for $1,2,5,15$ and $30 \mathrm{~min}$. Results are the means of three determinations, with their standard errors represented by vertical bars. Where no vertical bars are shown the standard errors fall within the experimental points as drawn. The initial concentrations of folates were: $0.5 \mu \mathrm{M}(\diamond), 1 \mu \mathrm{M}(\bigcirc), 2 \mu \mathrm{M}(\odot), 5 \mu \mathrm{M}(\triangle), 10 \mu \mathrm{M}(\Delta), 25 \mu \mathrm{M}(\square), 50 \mu \mathrm{M}(\square)$.

The initial velocity of folate uptake, relative to the concentration of MTHF and folic acid, was studied using a reaction time of $1 \mathrm{~min}$. Results for enterocytes are shown in Fig. $4(a)$ and those for brush-border-membrane vesicles in Fig. 4(b). Uptake rates increased with increasing folate concentration, being apparently linearly proportional to the initial folate concentration up to approximately 5-7 $\mu \mathrm{M}$, but showed a trend towards saturation at concentrations in excess of $50 \mu \mathrm{M}$.

Uptake of MTHF and folic acid at steady-state by enterocytes and brush-bordermembrane vesicles was studied using a reaction time of $30 \mathrm{~min}$ (Fig. $5(a, b)$ ). The magnitude of uptake increased rapidly with increasing folate concentrations up to $20 \mu \mathrm{M}$. At higher 

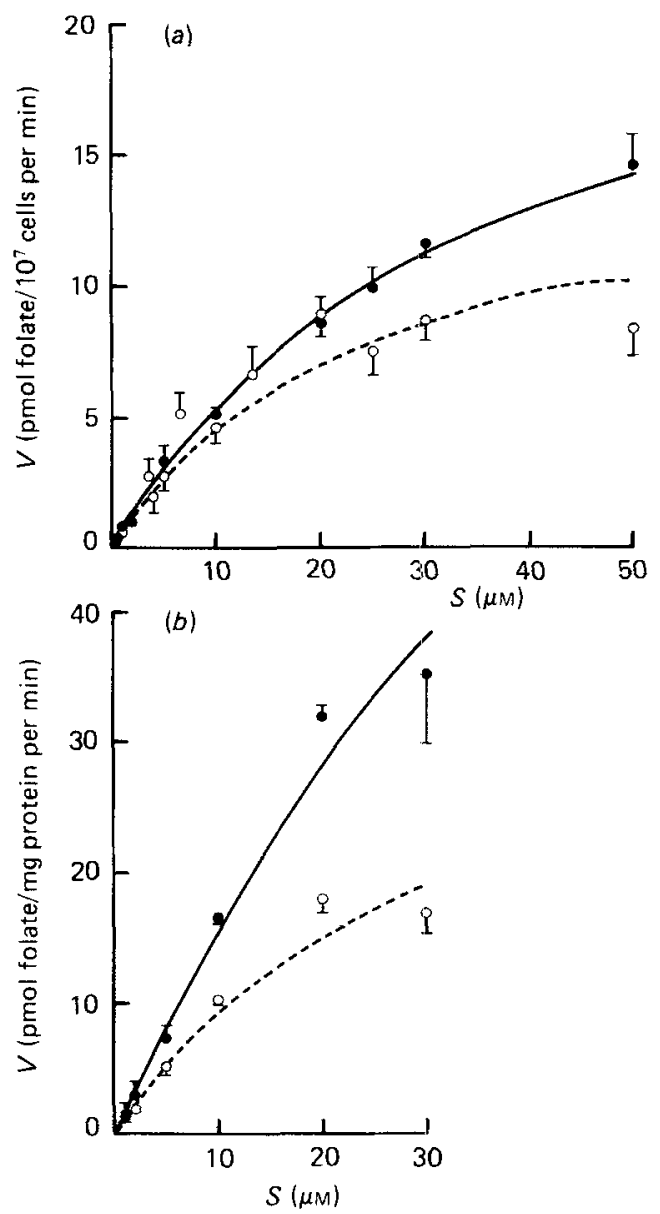

Fig. 4. The influence of substrate concentration $(S, \mu \mathrm{M})$ on the initial velocity of folate uptake $(V)$ by enterocytes and brush-border-membrane vesicles. (a) Enterocytes or $(b)$ brush-border-membrane vesicles were incubated with $1-50 \mu \mathrm{M} 5-\left[{ }^{14} \mathrm{C}\right]$ methyltetrahydrofolate $(\mathrm{MTHF})(\mathrm{O})$ or $\left[{ }^{3} \mathrm{H}\right]$ folic acid $(\mathbf{O})$ at $\mathrm{pH} 5 \cdot 0$ for $1 \mathrm{~min}$. Results for enterocytes are the means of three determinations whilst those for brush-bordermembrane vesicles are the means of six determinations, in both cases, with their standard errors represented by vertical bars. Where no bars are shown the standard errors fall within the experimental points as drawn. The curves were drawn as calculated using the MLP computer program.

folate concentrations the rate of increase of uptake declined and tended towards saturation with initial folate concentrations in excess of $50 \mu \mathrm{M}$. These features were observed both for MTHF and folic acid, and between enterocytes and brush-border-membrane vesicles.

Values for $K_{m}$ and $V_{\max }$ were calculated from plots of uptake at initial velocity and steady-state using the MLP computer program and are shown in Table $1 . K_{m}$ and $V_{\max }$ were similar, both between enterocytes and brush-border-membrane vesicles, and between MTHF and folic acid.

\section{DISCUSSION}

Brush-border-membrane vesicles and enterocytes isolated from the small intestine were chosen for these studies of folate absorption in the neonatal kid because they offered the opportunity of studying the initial stages of folate uptake under closely controlled 

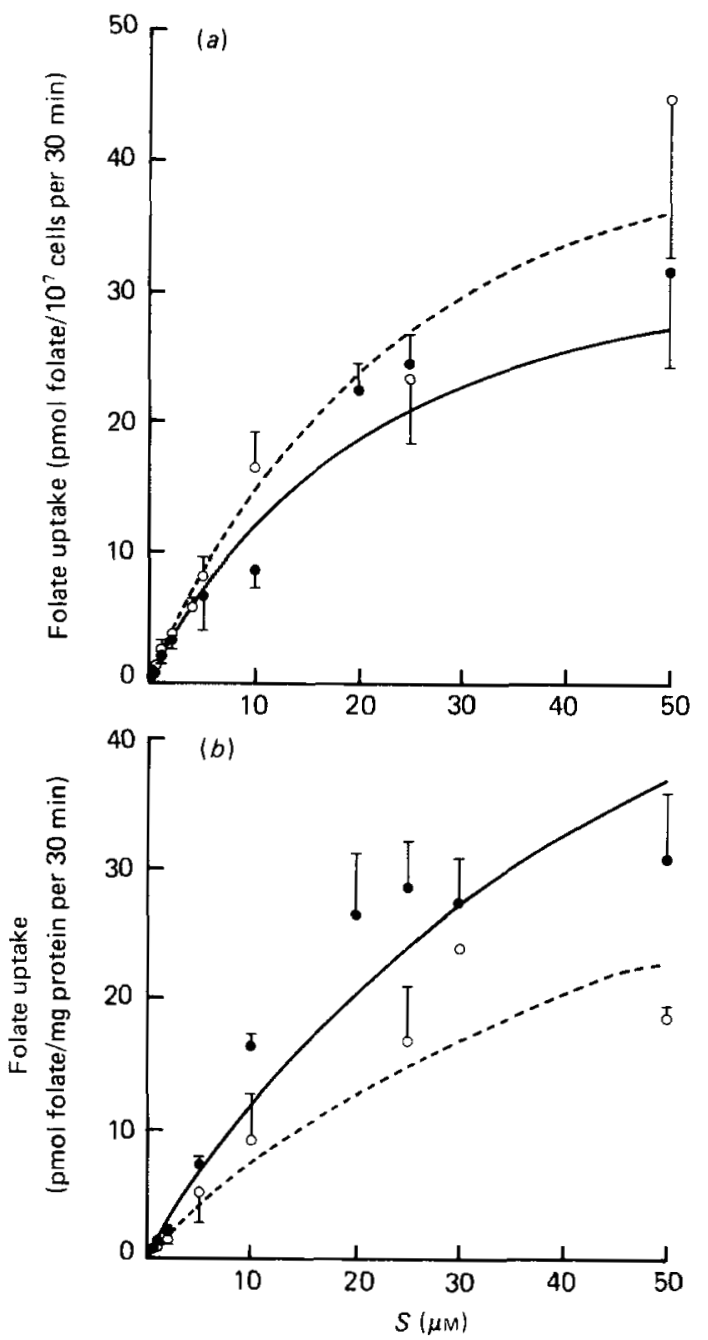

Fig. 5. Relation between uptake of folates by enterocytes and brush-border-membrane vesicles and free folate concentration under steady-state conditions. (a) Enterocytes or (b) brush-border-membrane vesicles were incubated with $1-50 \mu \mathrm{M} 5-\left[{ }^{14} \mathrm{C}\right]$ methyltetrahydrofolate (MTHF) (O) or $\left[{ }^{3} \mathrm{H}\right] \mathrm{folic}$ acid (O) at pH 5.0 for $30 \mathrm{~min}$. Results were plotted as folate taken up $v$. free unreacted folate $(S)$, at steady-state. Results for enterocytes are the means of three determinations, whilst those for brush-border-membrane vesicles are the means of six determinations, in both cases, with their standard errors represented by vertical bars. Where no bars are shown the standard errors fall within the experimental points as drawn. The curves were drawn as calculated using the MLP computer program.

conditions. In whole animals folate absorption studies are often difficult to interpret due to problems associated with the entero-hepatic circulation of folate via bile fluid, changes in digesta transit time and the difficulty of producing adequate control diets compatible with normal health. In other work with jejunal segments or everted sacs, it has been impossible to distinguish between factors consequent on the maintenance of the acidic microclimate (Blair \& Matty, 1974) at the glycocalyx and factors acting directly on the transport process. 
Table 1. Rate-constants for the uptake of folates by enterocytes (per $10^{7}$ cells for $\mathrm{V}_{\max }$ ) and brush-border-membrane vesicles (per $m g$ protein for $\mathrm{V}_{\text {max }}$ )

(Mean values of $K_{m}$ and $V_{\max }$, with their standard errors, for initial velocity kinetics and uptake at steady-state were calculated from the values in Figs. 4 and 5 respectively, using the MLP program as described on pp. 488-489)

\begin{tabular}{|c|c|c|c|c|}
\hline & \multicolumn{2}{|c|}{ Enterocytes } & \multicolumn{2}{|c|}{$\begin{array}{l}\text { Brush-border-membrane } \\
\text { vesicles }\end{array}$} \\
\hline & Mean & SE & Mean & $\mathbf{S E}$ \\
\hline \multicolumn{5}{|c|}{ (a) Initial velocity kinetics ( $1 \mathrm{~min}$ ) } \\
\hline \multicolumn{5}{|l|}{ Folic acid } \\
\hline$K_{m}(\mu \mathrm{M})$ & $55 \cdot 2$ & $39 \cdot 3$ & $62 \cdot 9$ & $14 \cdot 3$ \\
\hline$V_{\max }(\mathrm{pmol} / \mathrm{min})$ & $30 \cdot 6$ & $14 \cdot 4$ & $40 \cdot 3$ & $13 \cdot 0$ \\
\hline \multicolumn{5}{|l|}{ MTHF } \\
\hline$K_{m}(\mu \mathrm{M})$ & $50 \cdot 9$ & $32 \cdot 0$ & 40.8 & $12 \cdot 0$ \\
\hline$V_{\max }(\mathrm{pmol} / \mathrm{min})$ & $15-9$ & $8 \cdot 8$ & $46 \cdot 5$ & $11 \cdot 6$ \\
\hline \multicolumn{5}{|c|}{ (b) Uptake at steady-state $(30 \mathrm{~min})$} \\
\hline Folic acid & & & & \\
\hline$K_{m}(\mu \mathrm{M})$ & $49 \cdot 4$ & $24 \cdot 8$ & $55 \cdot 2$ & $30 \cdot 5$ \\
\hline$V_{\max }(\mathrm{pmol} / 30 \mathrm{~min})$ & $54 \cdot 6$ & $23 \cdot 5$ & $77 \cdot 8$ & $40 \cdot 6$ \\
\hline \multicolumn{5}{|l|}{ MTHF } \\
\hline$K_{m}(\mu \mathrm{M})$ & $43 \cdot 1$ & $27 \cdot 7$ & $58 \cdot 1$ & $27 \cdot 6$ \\
\hline$V_{\max }(\mathrm{pmol} / 30 \mathrm{~min})$ & $52 \cdot 8$ & $29 \cdot 9$ & $49 \cdot 7$ & $31 \cdot 1$ \\
\hline
\end{tabular}

MTHF, 5-methyltetrahydrofolate.

Enterocytes produced as described retained their structural integrity and viability for at least $8 \mathrm{~h}$ in a holding medium. Tests using Acridine Orange and ethidium bromide at frequent intervals during the course of experiments, showed that active transport mechanisms were maintained throughout the period (Lee et al. 1975; Parks et al. 1979). Enterocytes produced by the method described were discrete single cells and could therefore be accurately counted under the microscope and assayed by the same rapidfiltration technique used for the brush-border-membrane vesicles in transport experiments. This facilitated direct comparisons.

Both intact enterocytes and membrane vesicles demonstrated features characteristic of folate transport across the intact intestine, including marked $\mathrm{pH}$-dependence and saturable uptake of folates at low concentrations. It is clear therefore that these phenomena may be attributed to processes associated with the brush-border-membrane itself, and are not dependent on metabolic events within the intact cell. Indeed in other experiments on vesicles additions of physiological concentrations of ATP, NADP, glucose or glutamic acid were completely without effect (P. Blakeborough and D. N. Salter, unpublished results).

In common with the findings for rat intestinal brush-border-membrane vesicles (Selhub \& Rosenberg, 1981), transport of MTHF and folic acid in kid brush-border-membrane vesicles and enterocytes was optimal at $\mathrm{pH} \mathrm{5 \cdot 0.} \mathrm{This} \mathrm{contrasts} \mathrm{with} \mathrm{reports} \mathrm{that} \mathrm{uptake}$ from perfused rat jejunum (Elsborg, 1974) and in everted jejunal sacs (Strum, 1979) was optimal when the intralumen $\mathrm{pH}$ was 6.0 , but is perhaps more consistent with the existence of an acidic microenvironment with a $\mathrm{pH}$ closer to 5.0 than 6.0 immediately adjacent to the brush-border surface (Lucas \& Blair, 1978).

Experiments with cellobiose, a sugar which increases the osmolarity of the medium but is not absorbed, indicated that uptake of folates at the brush-border-membrane surface 
represented transport rather than binding. The inhibitory effect of such disaccharides is generally ascribed to shrinkage of intravesicular spaces due to the increasing osmotic pressure of the external fluids (Hopfer et al. 1973). Extrapolation of the plot of folic acid uptake $v$. the reciprocal of osmotic pressure indicated a slight positive uptake at infinite osmotic pressure. Apparently binding of folic acid to the membrane surface was not a major component of uptake under the conditions of the test at $\mathrm{pH} 5 \cdot 0$. However, the $\mathrm{pH}-$ dependence curve of MTHF uptake by brush-border-membrane vesicles showed a shoulder around $\mathrm{pH} 6.0$ very similar to that described for folic acid uptake by rat membrane vesicles by Selhub \& Rosenberg (1981), which may represent the binding activity of the membrane for folic acid reported to occur at higher pH values (Selhub et al. 1979).

The characteristics of folate transport studied in the experiments reported here indicate that the uptake processes described in brush-border-membrane vesicles were similar to those of intact enterocytes. Thus, transport of MTHF and folic acid was optimal at pH 5.0 for both tissue fractions. Also with brush-border-membrane vesicles and enterocytes the relation between transport of MTHF or folic acid and time was similar: it was rapid and linear for $2-5 \mathrm{~min}$, thereafter declining until steady-state was established in $10-30 \mathrm{~min}$. Results for the initial velocity of transport and steady-state uptake of MTHF and folic acid confirmed that the mechanism of uptake by kid brush-border-membrane vesicles, like that by rat membrane vesicles, was saturable. Similarly, transport of MTHF and folic acid by the isolated cells became saturated at concentrations in excess of $30 \mu \mathrm{M}$. It was not possible to distinguish a linear component of uptake at higher concentrations of the folates, as observed in the rat tissues (Selhub \& Rosenberg, 1981).

There are no previous reports of direct measurements of uptake of the naturally occurring form of folate, MTHF, using ${ }^{14} \mathrm{C}$-labelled 5-methyltetrahydrofolate in brushborder-membrane vesicles or enterocytes. However, other workers (Colman et al. 1981; Eilam et al. 1981 ; Selhub \& Rosenberg, 1981) used ${ }^{3} \mathrm{H}$-labelled pteroylmonoglutamate or ${ }^{3} \mathrm{H}$-labelled methotrexate, and results for MTHF were deduced by competition of unlabelled MTHF for the labelled folate. $K_{m}$ for the saturable components of uptake of MTHF and folic acid respectively were similar for brush-border-membrane vesicles $(40.8$ and $62.9 \mu \mathrm{M})$ and enterocytes $(50.9$ and $55.2 \mu \mathrm{M})$ in the present experiments, and agreed with $K_{m}$ values for folic acid transport in enterocytes from 2-6-week-old chicks (Eilam et al. 1981). However, they were an order of magnitude higher than those reported for folic acid transport in adult rat brush-border-membrane vesicles (Selhub \& Rosenberg, 1981). It is possible that the transport systems for MTHF in neonatal kid intestine had not yet reached their full potential; otherwise, these may represent species differences. The observation that transport of MTHF and folic acid showed a common optimum at $\mathrm{pH} 5 \cdot 0$ supports other evidence (Selhub \& Rosenberg, 1981) that the mechanism of uptake is not based entirely on passive diffusion of non-ionized forms of folate (Blair \& Matty, 1974). The findings support the concept of a $\mathrm{pH}$-dependent channel or carrier in the brush-border membrane. That the $K_{m}$ values derived from studies of uptake at initial velocity and steady-state were similar for both membrane vesicles and enterocytes suggests a single mechanism of folate transport in each. Saturation of the uptake mechanism at approximately the same concentration in enterocytes and membrane vesicles seems to suggest that there was little loss of folate by transport of folate out of the cell across the basolateral membrane. This would not be unexpected if transport at the basolateral membrane were optimal at the normally neutral $\mathrm{pH}$ prevailing within the intracellular environment.

It may be concluded that both isolated enterocytes and brush-border-membrane vesicles constitute useful in vitro systems for studying the mechanisms of absorption of folates in the small intestine. Clearly, although viable enterocytes represent a more-complete metabolic system, they are difficult to maintain in culture, requiring complex media, and 
all the components necessary for the initial phase of folate uptake are present in the brushborder membrane. The similarity of transport characteristics measured with enterocytes and brush-border-membrane vesicles provides additional evidence that the latter retain structural and functional integrity despite the high shearing forces used in their preparation, and the long storage life of the membranes (at least 6 months at $-20^{\circ}$ ) is a considerable practical advantage.

The authors are pleased to acknowledge the assistance of Ms Sheila G. Neville with the research, and the efficient management and handling of the goats by $\mathrm{Mr}$ Alan Mowlem. They are grateful to Professor R. R. Dils for reading the manuscript and to Mr S. Kirby for his aid with the computer programs. Ox pituitary extract was a gift from Dr I. C. Hart, Coopers Animal Health, Berkhamsted.

\section{REFERENCES}

Bensadoun, A. \& Weinstein, D. (1976). Analytical Biochemistry 70, 241-250.

Blair, J. A. \& Matty, A. J. (1974). Clinics in Gastroenterology 3, 183-197.

Blakeborough, P. \& Salter, D. N. (1985). Abstracts of the XIII International Congress of Nutrition, Brighton, p. 149.

Booth, A. G. \& Kenny, A. J. (1974). Biochemical Journal 142, 575-581.

Colman, N., Hettiarachchy, N. \& Herbert, V. (1981). Science 211, 1427-1429.

Eilam, Y., Ariel, M., Jablonska, M. \& Grossowicz, N. (1981). American Journal of Physiology 240, G170G175.

Elsborg, L. (1974). Danish Medical Bulletin 21, 1-11.

Ferland, S. \& Hugon, J. S. (1979). In Vitro 15, 288-293.

Ford, W. L. (1979). In Handbook of Experimental Immunology, vol. 2, Cellular Immunology, pp. 23.10-23.22 [D. M. Weir, editor]. Oxford: Blackwell.

Hopfer, U., Nelson, K., Perrotto, J. \& Isselbacher, K. I. (1973). Journal of Biological Chemistry 248, $25-32$.

Lee, S.-K., Singh, J. \& Taylor, R. B. (1975). European Journal of Immunology 5, 259-262.

Lucas, M. L. \& Blair, J. A. (1978). Proceedings of the Royal Society of London. Series A 200, $27-41$.

Moyer, M. P. (1983). Proceedings of the Society for Experimental Biology and Medicine 174, 12-15.

Murer, H., Ammann, E., Biber, J. \& Hopfer, U. (1976). Biochimica et Biophysica Acta 433, 509-519.

Parks, D. R., Bryan, V. M., Oi,V. T. \& Herzenberg, L. A. (1979). Proceedings of the National Academy of Sciences, USA 76, 1962-1966.

Selhub, J., Gay, A. C. \& Rosenberg, I. H. (1979). In The Chemistry and Biology of the Pteridines, pp. 593-596

[R. Kisliuk and G. M. Brown, editors]. Amsterdam: Elsevier/ North Holland Press.

Selhub, J. \& Rosenberg, I. H. (1981). Journal of Biological Chemistry 256, 4489-4493.

Strum, W. B. (1979). Biochimica et Biophysica Acta 554, 249-257.

Watford, M., Lund, P. \& Krebs, H. A. (1979). Biochemical Journal 178, 589-596. 